\title{
Comparison of high-resolution Scheimpflug and high-frequency ultrasound biomicroscopy to anterior-segment OCT corneal thickness
}

\section{measurements}

Anastasios John

Kanellopoulos ${ }^{1,2}$

George Asimellis'

'Laservision.gr Eye Institute, Athens, Greece; ${ }^{2} \mathrm{New}$ York University Medical School, New York, NY, USA

\author{
This article was published in the following Dove Press journal: \\ Clinical Ophthalmology \\ 19 November 2013 \\ Number of times this article has been viewed
}

Background: The purpose of this study was to compare and correlate central corneal thickness in healthy, nonoperated eyes with three advanced anterior-segment imaging systems: a high-resolution Scheimpflug tomography camera (Oculyzer II), a spectral-domain anteriorsegment optical coherence tomography (AS-OCT) system, and a high-frequency ultrasound biomicroscopy (HF-UBM) system.

Methods: Fifty eyes randomly selected from 50 patients were included in the study. Inclusion criteria were healthy, nonoperated eyes examined consecutively by the same examiner. Corneal imaging was performed by three different methods, ie, Oculyzer II, spectral-domain AS-OCT, and FH-UBM. Central corneal thickness measurements were compared using scatter diagrams, Bland-Altman plots (with bias and 95\% confidence intervals), and two-paired analysis.

Results: The coefficient of determination $\left(r^{2}\right)$ between the Oculyzer II and AS-OCT measurements was 0.895 . Likewise, the coefficient was 0.893 between the Oculyzer II and HF-UBM and 0.830 between the AS-OCT and HF-UBM. The trend line coefficients of linearity were 0.925 between the Oculyzer II and the AS-OCT, 1.006 between the Oculyzer II and HF-UBM, and 0.841 between the AS-OCT and HF-UBM. The differences in average corneal thickness between the three pairs of CCT measurements were $-6.86 \mu \mathrm{m}$ between the Oculyzer II and HF-UBM, $-12.20 \mu \mathrm{m}$ between the AS-OCT and Oculyzer II, and $+19.06 \mu \mathrm{m}$ between the HFUBM and AS-OCT.

Conclusion: The three methods used for corneal thickness measurement are highly correlated. Compared with the Scheimplug and ultrasound devices, the AS-OCT appears to report a more accurate, but overally thinner corneal pachymetry.

Keywords: anterior eye segment, high-frequency ultrasound biomicroscopy, optical coherence tomography, high-resolution Pentacam, corneal thickness

\section{Introduction}

Accurate, precise, and repeatable measurement of corneal thickness has become increasingly important in the decision-making process for refractive surgery, as well as in short-term and long-term postoperative assessment. For example, overestimation of corneal thickness could, in principle, incorrectly deem a patient suitable for laser in situ keratomileusis, while underestimation could lead to rejection of this option. In addition, corneal thickness mapping is critical in evaluation and assessment of corneal ectatic disorders, such as keratoconus. ${ }^{1}$

For these reasons, significant and continuous development of computerized anterior-segment imaging methods aiming at repeatable, accurate, and precise corneal
Correspondence: A John Kanellopoulos Laservision.gr Eye Institute, 17 Tsocha

Street, Athens, Greece 11521

Tel +302107472777

Fax +30 21 07472789

Email ajk@brilliantvision.com 
thickness mapping is highly desirable. Most corneal imaging technologies are optical, although ultrasound imaging has also been used extensively in clinical practice.

Several studies have been published in the peer-reviewed literature ${ }^{2-10}$ on the subject of assessing the interchangeability of quantitative imaging of the anterior-segment (and specifically, corneal thickness), between various optical modalities and ultrasound pachymetry.

It has been found in some of these studies ${ }^{5}$ that ultrasound produces corneal pachymetry measurements that are significantly different from those made by optical coherence tomography and/or Scheimpflug imaging. A possible source for the large variability associated with contact ultrasound pachymetry could be the manual point sampling. In addition, an oblique incidence may produce thicker measurements.

Our clinical experience using both a Scheimpflug imaging camera and an anterior-segment optical coherence tomography (AS-OCT) system ${ }^{11}$ has been indicative of a systematic difference in corneal thickness measurements reported between the AS-OCT and Pentacam.

The aim of this work was to compare and correlate central corneal thickness measured in healthy, nonoperated eyes using three of the most advanced anterior-segment imaging systems: a high-resolution Scheimpflug rotating camera (WaveLight $^{\circledR}$ Oculyzer $^{\mathrm{TM}}$ II, Oculus Optikgeräte GmbH, Wetzlar, Germany), a spectral-domain AS-OCT (RTVue-100, Optovue Inc, Fremont, CA, USA), and a highfrequency ultrasound biomicroscopy (HF-UBM) system (Artemis II, Artemis Medical Technologies Inc, Vancouver, British Columbia, Canada). To the best of our knowledge, this noncontact (despite the fluid coupling, the probe is not in contact to the corneal surface) scanning HF-UBM system has not been clinically compared for central corneal thickness with these two most current optical anterior-segment modalities. In an era when AS-OCT devices have become established in clinical practice for providing corneal thickness maps, this study may provide a valuable benchmark for comparison with Scheimpflug-derived corneal thickness measurements.

\section{Materials and methods}

This study was approved by the ethics committee at our institution, and was adherent to the tenets of the Declaration of Helsinki. Informed consent was obtained from all adult subjects participating in the investigation and from the parents and/or legal guardians of participating minors. The study was conducted in our clinical practice on patients during their regular scheduled visit.
Inclusion criteria were healthy nonoperated normal eyes with no ocular pathology other than refractive error. A complete ocular evaluation was performed to screen for corneal abnormalities. The prime reasons for exclusion from the study were previous eye surgery on that study eye, irritation, and trauma. To avoid any potential artifacts, imaging preceded the ocular examination for all three methods. Given that all three instruments provide a live image of the pupil to allow centration, pupil centration was used to ensure proper measurement of central corneal thickness.

The Scheimpflug diagnostic device used was the WaveLight Oculyzer II. The Oculyzer is a high-resolution Pentacam camera ${ }^{12}$ which is incorporated into the Alcon/ WaveLight refractive suite. ${ }^{13}$ The AS-OCT system used was the RTVue-100, an anterior-segment Fourier-domain optical coherence tomography system, and the HF-UBM imaging system used was the Artemis II+ superior.

The same investigator performed all measurements on the subjects using each modality. Each subject's corneal thickness was measured by the three modalities at the same time of day in the order of Oculyzer II, AS-OCT, and Artemis II. The Oculyzer II pachymetry measurements ( $9 \mathrm{~mm}$ diameter) were obtained and processed by Oculyzer examination software (version 1.17r91). The default setting of 25 images per acquisition was used.

The AS-OCT pachymetry measurements were obtained and processed using RTVue A6 software $(9,0,27)$. The scan rate was 26,000 axial scans per second, the axial resolution was $5 \mu \mathrm{m}$, and the transverse resolution was $15 \mu \mathrm{m}$ using the L-Cam accessory lens. Eight meridional B-scans were used per acquisition, consisting of 1,024 A-scans each, covering a $6 \mathrm{~mm}$ corneal diameter. Following correct fixation and centering, acquisition time was in the order of a few seconds for both optical modalities. ${ }^{14}$

The HF-UBM pachymetry measurements $(9 \mathrm{~mm}$ diameter) were obtained and processed using Zeus version 1.0 (Build 11.780) software licensed from Artemis Medical Technologies Inc. During acquisition, the center of rotation of the system was adjusted until it was coaxial with the pupil center, as observed from the internal camera image. Following correct fixation and centering, acquisition time was in the order of 5 minutes. The setting was four meridional B-scans per acquisition, consisting of $256 \mathrm{~A}$-scans each, $8 \mathrm{~mm}$ in diameter. Of the two options for corneal analysis mode offered, the option "centered on the middle of the scan" was selected and not "circle-filter to smooth the map".

Descriptive and comparative statistics, analysis of variance between the three modes, and linear regression were 
performed with statistics tools provided by Minitab version 16.2.3 (MiniTab Ltd, Coventry, UK) and Origin Lab version 9 (OriginLab Corporation, Northampton, MA, USA).

We employed scatter diagrams showing the regression line of corneal thickness measurements between pairs (ie, Oculyzer versus HF-UBM, HF-UBM versus AS-OCT, and Oculyzer versus AS-OCT). Due to the bias found for each pair, the linear fit curves were not forced to the intercept point of $(0,0)$. In each pair of modalities, and for the same measurements of central corneal thickness, the coefficient of determination $\left(r^{2}\right)$ and the linear curve fit coefficient of linearity is reported, showing the regression line, the $95 \%$ confidence interval line, and the $95 \%$ prediction intervals. In addition, Bland-Altman plots comparing central corneal thickness measurements between the pairs were constructed, showing the upper and lower limits of agreement. Paired-analysis $P$-values less than 0.05 were considered to be statistically significant.

\section{Results}

Fifty cases (18 female, 32 male) were studied over a 3-month period during their scheduled visits to our practice. Twenty-three cases were right eyes (OD) and 27 were left (OS) eyes. Subject age ranged from 17 to 68 (average $32.1 \pm 12.3$ ) years.

Tables 1 and 2 report mean values for central corneal thickness as well as comparative statistics for the three groups. Examples of three-dimensional pachymetry maps for the same eye obtained via the three modalities are presented in Figure 1. Intra-individual repeatability studies, performed on same-eye measurements with the three modalities indicate the following standard deviations: Oculyzer II, $\pm 6.5 \mu \mathrm{m}$; Artemis HF-UBM, $\pm 8.7 \mu \mathrm{m}$; Optovue AS-OCT, $\pm 3.2 \mu \mathrm{m}$.

The HF-UBM had a mean central corneal thickness of $545.1 \pm 28.3$ (range 596-474) $\mu \mathrm{m}$; the AS-OCT mean was $525.8 \pm 31.2$ (range 590-432) $\mu \mathrm{m}$ and the Oculyzer II mean was 538.0 \pm 30.7 (range 586-447) $\mu \mathrm{m}$. The standard deviation for all measurements was in the order of $\pm 28-31 \mu \mathrm{m}$, or approximately $7 \%$ of the corresponding values. The central

Table I Descriptive statistics for CCT as measured by the three modalities

\begin{tabular}{llll}
\hline CCT & AS-OCT & Oculyzer II & HF-UBM \\
\hline Mean $(\mu \mathrm{m})$ & 525.8 & 538.0 & 545.1 \\
SD $(\mu \mathrm{m})$ & \pm 31.2 & \pm 30.7 & \pm 28.3 \\
Maximum $(\mu \mathrm{m})$ & 590 & 586 & 596 \\
Minimum $(\mu \mathrm{m})$ & 432 & 447 & 474 \\
Normality $P$ & 0.218 & 0.173 & $0.74 \mathrm{I}$ \\
\hline
\end{tabular}

Abbreviations: AS-OCT, anterior-segment optical coherence tomography; CCT, central corneal thickness; HF-UBM, high-frequency ultrasound biomicroscopy; $\mathrm{SD}$, standard deviation. corneal thickness data distribution for the three modalities is shown in Figure 2 in the form of box plots.

Comparative statistics (Table 2) for central corneal thickness shows a bias of $-6.86 \mu \mathrm{m}$ for the Oculyzer II and HF-UMB pair, $-12.20 \mu \mathrm{m}$ for the AS-OCT and Oculyzer II pair, and $+19.06 \mu \mathrm{m}$ for the HF-UBM and AS-OCT pair. The estimated standard deviation of the differences was similar between the three pairs.

Figure 3A compares the HF-UBM ( $\mathrm{x}$ axis) measurements with those of the Oculyzer II (y axis). A highly correlated group of data $\left(r^{2}=0.893\right)$ can be observed with a trend line (linear fit) coefficient of linearity of 1.006. These findings are supported by the Bland-Altman plot (Figure 3B).

Figure 4A compares central corneal thickness measurements for HF-UBM with those for AS-OCT. A slightly less correlated group of data $\left(r^{2}=0.830\right)$ can be observed, with a coefficient of linearity of 0.8412 . The thinner than average central corneal thickness measurements provided by OCT (in comparison with the same corneas as measured by HFUBM) is supported by the corresponding Bland-Altman plot (Figure 4B).

Figure 5A compares central corneal thickness measurements for the AS-OCT with those for the Oculyzer II. This set of data has an also excellent correlation (coefficient of determination $\left.r^{2}=0.895\right)$ with the trend line coefficient of linearity of 0.929 . The slightly thinner than average central corneal thickness measurements, as provided by optical coherence tomography (in comparison with the same corneas measured by the Oculyzer II), is supported by the corresponding Bland-Altman plot (Figure 5B). With very few exceptions, in which AS-OCT yielded larger readings (up to $+20 \mu \mathrm{m}$ ) than the Oculyzer, the trend was that the AS-OCT measurements were smaller than the corresponding Oculyzer readings by a mean of $-12.20 \mu \mathrm{m}$.

\section{Discussion Optically-based anterior-segment imaging technologies}

Optically-based anterior-segment imaging technologies are well established because of their excellent resolution, fast acquisition (few seconds), and naturally aided alignment. The three major optical systems for anterior-segment imaging are scanning slit-lamp combined with topography ${ }^{15}$ (eg, Orbscan), AS-OCT, and rotating Scheimpflug camera systems (eg, Pentacam).

Today's most advanced AS-OCT systems use Fourier spectral-domain signal processing featuring higher imaging speed and increased image resolution, in comparison with 
Table 2 Comparative statistics for the three pairs of imaging modalities examined

\begin{tabular}{llll}
\hline & HF-UBM versus & AS-OCT versus & Oculyzer II versus \\
& Oculyzer II & HF-OCT & -6.86 \\
\hline Estimated mean of the differences $(\mu \mathrm{m})$ & +19.06 & -12.20 & \pm 9.85 \\
Estimated SD of the differences $(\mu \mathrm{m})$ & \pm 12.62 & \pm 10.01 & $(-9.66,-4.06)$ \\
$95 \%$ Cl for mean difference $(\mu \mathrm{m})$ & $(15.47,22.65)$ & $-15.05,-9.35)$ & -4.92 \\
$t$-test of mean difference $=0$ (versus not $=0)$ & +10.68 & -8.61 & 0.0003 \\
$t$-value $(\mu \mathrm{m})$ & & & 0.0002 \\
$t$-test of mean difference $=0$ (versus not $=0)$ P-value & $<0.000 \mathrm{I}$ & 0.895 & 0.893 \\
Coefficient of determination $\left(r^{2}\right)$ & 0.830 & 0.9295 & 1.006 \\
Coefficient of linearity & 0.8412 & \\
\hline
\end{tabular}

Abbreviations: CCT, central corneal thickness; AS-OCT, anterior-segment optical coherence tomography; HF-UBM, high-frequency ultrasound biomicroscopy; Cl, confidence interval.

A

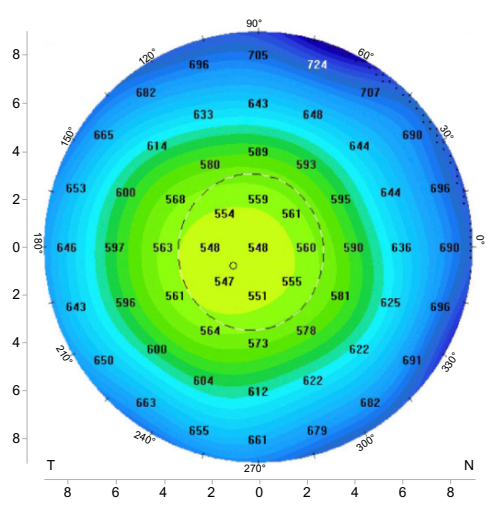

B

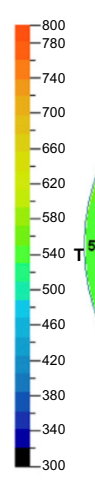

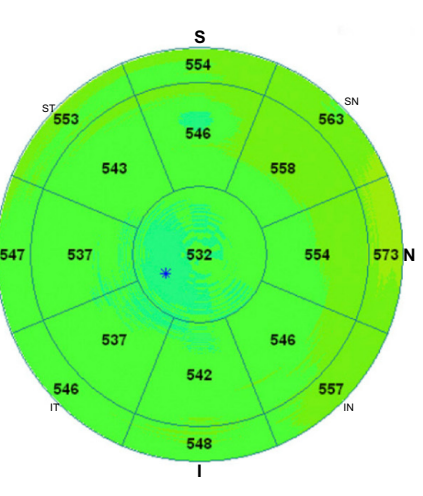

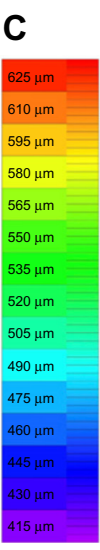

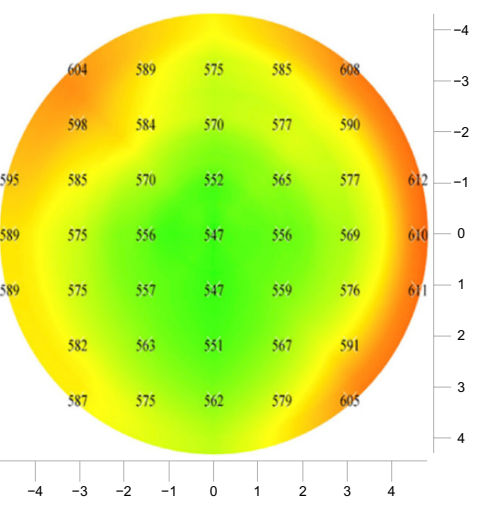

Figure I Corneal thickness maps of a cornea from the same subject obtained sequentially on the same day by (A) Oculyzer II Scheimpflug camera, (B) OptoVue AS-OCT, and (C) Artemis II HF-UBM. We observe "thinner measurements" of corneal thickness (eg, centrally) by the AS-OCT versus the Scheimpflug and the HF-UBM (-15 $\mu \mathrm{m})$. Abbreviations: AS-OCT, anterior-segment optical coherence tomography; CCT, central corneal thickness; HF-UBM, high-frequency ultrasound biomicroscopy.

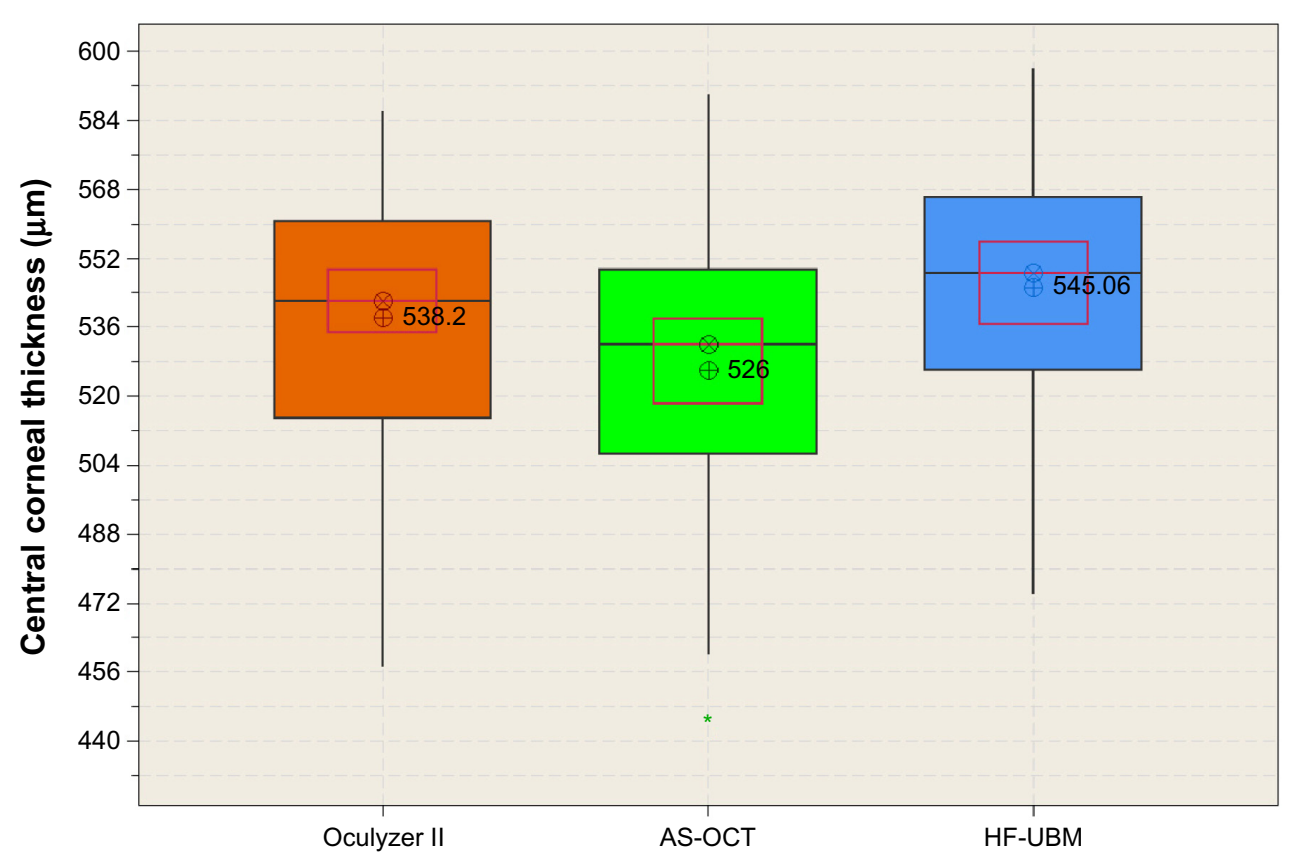

Figure 2 Corneal thickness measurement by the three modalities in the form of box plots. Median level is indicated by $\otimes$, average by $\oplus$, the $95 \%$ median confidence range box by the red borderline, and the interquartile intervals range box by the black borderline.

Abbreviations: AS-OCT, anterior-segment optical coherence tomography; HF-UBM, high-frequency ultrasound biomicroscopy. 

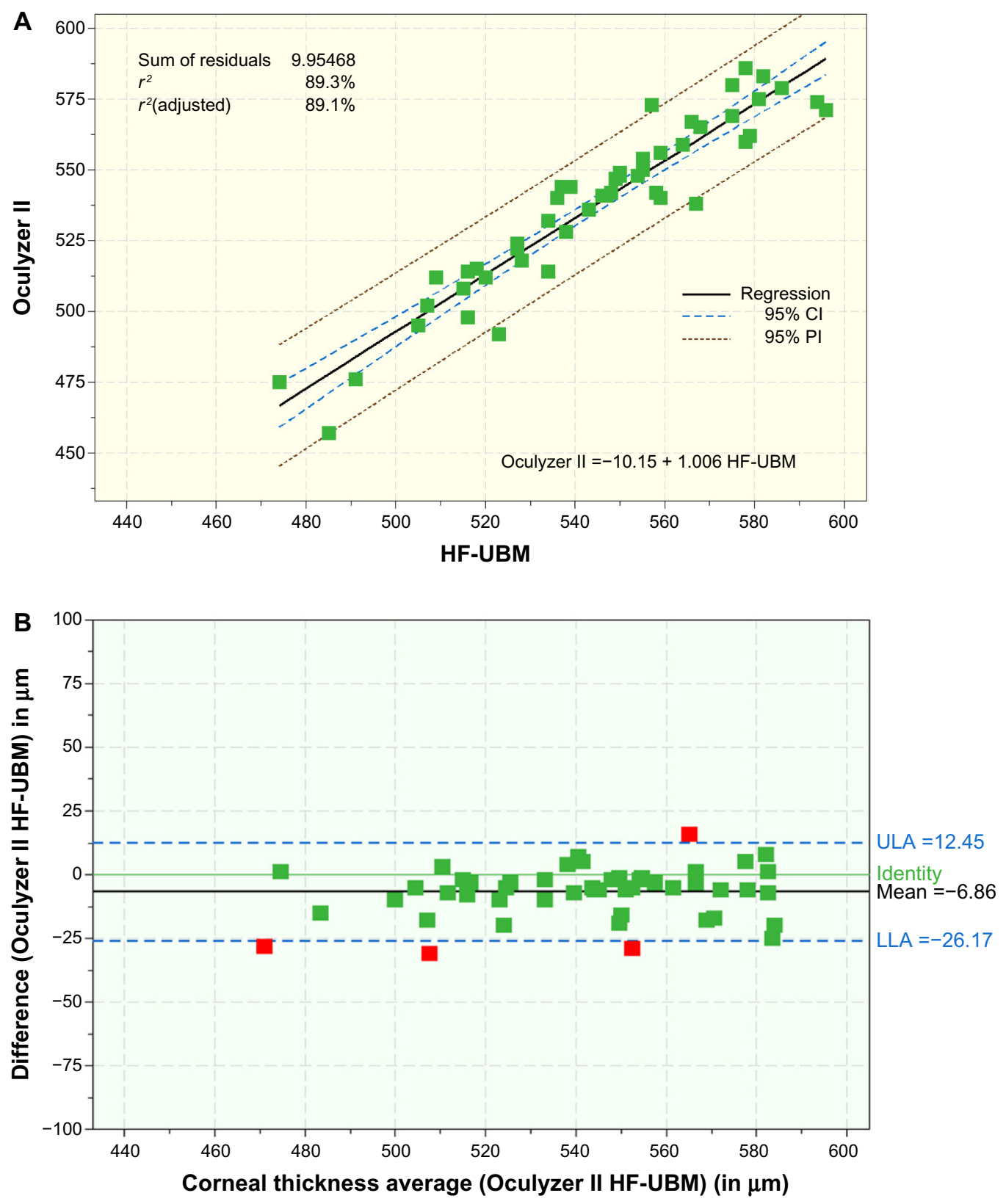

Figure 3 (A) Scatter diagram showing the regression line of CCT measurements (all units in $\mu \mathrm{m}$ ) between HF-UBM and the Oculyzer II with coefficient of determination ( $r^{2}$ ), (B) Bland-Altman plot comparing CCT measurements with HF-UBM and the Oculyzer II with mean bias and $95 \%$ upper and lower limits of agreement.

Abbreviations: AS-OCT, anterior-segment optical coherence tomography; CCT, central corneal thickness; HF-UBM, high-frequency ultrasound biomicroscopy; $\mathrm{Cl}$, confidence interval; LLA, lower limit of agreement; ULA, upper limit of agreement; PI, prediction interval.

the earlier generation of time-domain optical coherence tomography systems. ${ }^{16,17}$

As of today, there are a number of different spectraldomain optical coherence tomography systems commercially available, ${ }^{18}$ including the RTVue, OCT/SLO combination imaging system (Optos Inc, Marlborough, MA, USA), SS-1000 CASIA (Tomey Corporation, Nagoya, Japan), ${ }^{19}$ Copernicus SOCT (OptoPol Technology SA, Zawiercie, Poland) ${ }^{20}$ and the Spectralis OCT (Heidelberg Engineering GmbH, Heidelberg, Germany). ${ }^{21}$ Typically, optical coherence tomography systems provide three-dimensional pachymetric maps (via interpolation of the thickness profile corresponding to each meridional scan) as well as high-resolution crosssectional images along select meridians. ${ }^{22}$

Systems based on rotating Scheimpflug cameras, on the other hand, are designed for reconstruction of the anteriorsegment (such as anterior chamber depth and volume), as well as two-dimensional corneal mapping, including corneal pachymetry, anterior and posterior corneal curvature, total corneal refractive power, and anterior and posterior elevation. 

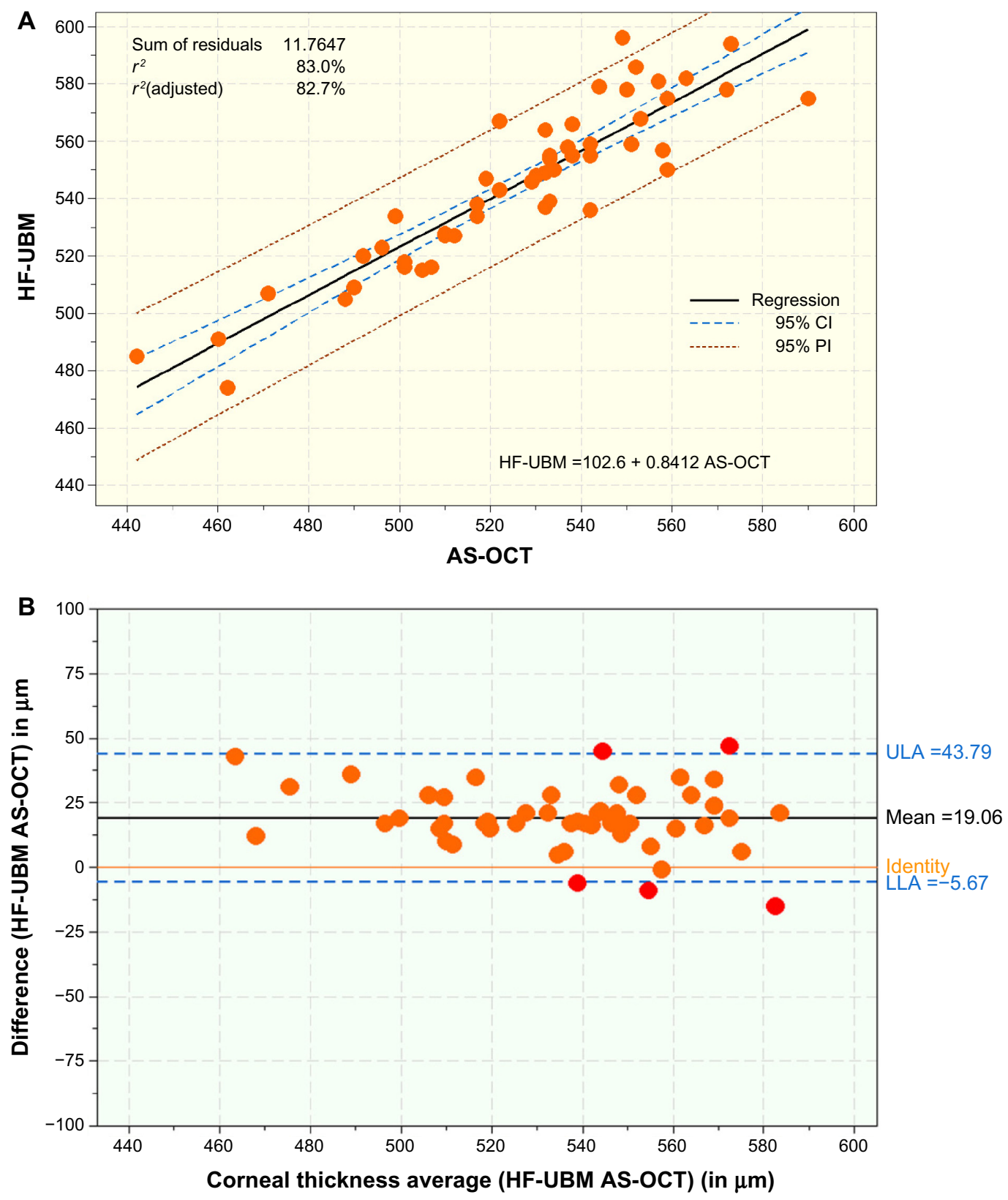

Figure 4 (A) Scatter diagram showing the regression line of CCT measurements $(\mu \mathrm{m})$ between HF-UBM and AS-OCT with coefficient of determination $\left(r^{2}\right)$. (B) Bland-Altman plot comparing CCT measurements $(\mu \mathrm{m})$ HF-UBM and AS-OCT measurements $(\mu \mathrm{m})$, mean bias and $95 \%$ upper and lower limits of agreement.

Abbreviations: AS-OCT, anterior-segment optical coherence tomography; CCT, central corneal thickness; HF-UBM, high-frequency ultrasound biomicroscopy; $\mathrm{Cl}$, confidence interval; LLA, lower limit of agreement; ULA, upper limit of agreement; PI, prediction interval.

The prominent system in this class is the Pentacam, ${ }^{23}$ the most recent update of which is the high-resolution Pentacam HR. ${ }^{24,25}$ In recent years, more Scheimpflug imaging instruments have become commercially available, including the Galilei G6 dual-Scheimpflug analyzer (Ziemer Ophthalmic Systems AG, Port, Switzerland), with dual rotating Scheimpflug cameras and a Placido topography system, ${ }^{26}$ the Sirius (Costruzione Strumenti Oftalmici, Scandicci, Italy), and the TMS-5 (Tomey Corporation). ${ }^{27}$ As with the OCT systems, acquisition is fast, and, due to the rotating slit-like beam, there is a common point (eg, the corneal apex) of reference for all sequential images.

\section{Ultrasound anterior-segment imaging technologies}

The principle of operation of the ultrasound technique lies in the reflection of an elastic wave from an interface because of the change in the medium's impedance..$^{28}$ The major advantage of ultrasound over optically based systems is that they are not hindered by optically opaque intervening ocular struc- 



Figure 5 (A) Scatter diagram showing the regression line of CCT measurements $(\mu \mathrm{m})$ between the OCT and Oculyzer II. (B) Bland-Altman plot comparing CCT measurements $(\mu \mathrm{m})$ and OCT and Oculyzer II measurements $(\mu \mathrm{m})$, with mean bias and $95 \%$ upper and lower limits of agreement.

Abbreviations: AS-OCT, anterior-segment optical coherence tomography; CCT, central corneal thickness; Cl, confidence interval; LLA, lower limit of agreement; ULA, upper limit of agreement; PI, prediction interval.

tures. Ultrasound systems, however, require fluid coupling to the eye, resulting in a less practical process.

There has been a lot of evolution since the simple onedimensional (A-scan) ultrasound systems, which are mainly contact (and thus require local corneal anesthesia). Their disadvantage is possible corneal compression by the probe and the risk of epithelium scarring, corneal injury, and infection.

The evolution of conventional noncontact B-scanning (two-dimensional brightness scan), known as ultrasound biomicroscopy, ${ }^{29}$ has been useful in assessment of many corneal pathologies including edema, ${ }^{30}$ keratoconus, ${ }^{31}$ dystrophies,${ }^{32}$ corneal scars, ${ }^{33}$ trauma, ${ }^{34}$ and corneal keloid. ${ }^{35}$ The most advanced digital ultrasound high-frequency $(35-50 \mathrm{mHz})$, noncontact arc-scanning ultrasound biomicroscopy system is the Artemis II. ${ }^{36}$

\section{Comparison of corneal pachymetry measurements}

Compared with the HF-UBM, each optical method has its particular advantages and disadvantages ${ }^{2,3}$ in terms of providing 
precise and accurate corneal mapping. The two optical modalities are significantly faster with regard to overall acquisition time. Mainly due to the eye recentration required for each sequential meridional scan, as well as potential patient discomfort during the examination, the HF-UBM requires at least five minutes per eye. Regarding the extent of corneal area imaged, the Oculyzer II and HF-UBM map approximately the same corneal area (9 mm diameter), while the AS-OCT maps a smaller area (6 $\mathrm{mm}$ diameter).

Our results indicate a high degree of correlation between the three modalities. While this is expected, given that the same quantity was measured, the residual differences are of greater interest. The Bland-Altman comparisons, as well as the bias results (Table 2), indicate that central corneal thickness measurements follow a trend of HFUBM $>$ Oculyzer II >AS-OCT.

Our results are similar to those reported in the literature ${ }^{4-9}$ whereby older diagnostic ultrasound, UBM, and Orbscan were correlated. In more related studies, ${ }^{8,9}$ where AS-OCT corneal thickness measurements were compared against the Scheimpflug and hand-held ultrasound in which the reported corneal thickness difference between the Scheimpflug and AS-OCT has been found to be $10.4 \mu \mathrm{m}$. This compares with a similar study by Chen et $\mathrm{al}^{6}$ in which the same two optical instruments were used. Although that study reports different mean central corneal thickness values, which can be attributed to the different geographic origins of the study population, the average difference in corneal thickness measurements between the Scheimpflug and AS-OCT is reported to be $+11 \mu \mathrm{m}$. The large span of ages in the sample group might have been better addressed if divided in age groups, given the known dependency of corneal thickness decrease including the Bowman's membrane, ${ }^{37}$ and perhaps, opacity and stray light scatter increase with age, ${ }^{38}$ which may adversely affect the reported pachymetry.

The slight difference between the optical (slightly thinner) and ultrasound (slightly thicker) pachymetry measurements can be attributed to the fact that the optical modalities may be influenced by tear film, including the hydrated epithelial layer of the cornea and the posterior corneal surface, while ultrasonic pachymetry utilizes ultrasound echoes from the posterior cornea to calculate corneal thickness. Therefore, the optical modalities face the problem of correcting for refraction by the curved corneal surface, irregularities of tear film, and possibly differences in definition of the posterior surface. ${ }^{10}$ Our clinical experience of simultaneous employment of these three modalities in corneal pachymetry measurements suggests that the OCT offers more accurate identification of corneal structures - even in cases of compromised corneal clarity and an irregular cornea surface. This fact, in addition to the higher axial resolution and the reduced intra-individual repeatability provided by the OCT, indicate that the anteriorsegment OCT may be offering the most accurate and precise corneal thickness measurements of the three modalities examined in this study.

\section{Conclusion}

AS-OCT appears to report more accurate, and slightly thinner corneal pachymetry measurements by an average of $-20 \mu \mathrm{m}$ when compared with HF-UBM, and by an average of -12 $\mu \mathrm{m}$ when compared with the Scheimpflug system. Given the increasing clinical applications of AS-OCT in corneal imaging and pachymetry, we believe that this is a very interesting finding that may help to adjust corneal thickness determination.

\section{Disclosure}

No grants and/or other financial support, either monetary or in kind, were received in relation to this work. AJ Kanellopoulos is a consultant to Alcon WaveLight. G Asimellis has no conflicts of interest in this work.

\section{References}

1. Zadnik K, Steger-May K, Fink BA, et al. Collaborative longitudinal evaluation of keratoconus. Between-eye asymmetry in keratoconus. Cornea. 2002;21(7):671-679.

2. Nolan W. Anterior segment imaging: ultrasound biomicroscopy and anterior segment optical coherence tomography. Curr Opin Ophthalmol. 2008;19(2):115-121.

3. Bechman M, Thiel MJ, Neubauer AS, et al. Central corneal thickness measurements with a retinal optical coherence tomography device versus standard ultrasonic pachymetry. Cornea. 2001;20(1):50-54.

4. Paul T, Lim M, Starr CE, Lloyd HO, Coleman DJ, Silverman RH. Central corneal thickness measured by the Orbscan II system, contact ultrasound pachymetry, and the Artemis 2 system. J Cataract Refract Surg. 2008;34(11):1906-1912.

5. Nam SM, Im CY, Lee HK, Kim EK, Kim Ti, Seo KY. Accuracy of RTVue optical coherence tomography, Pentacam, and ultrasonic pachymetry for the measurement of central corneal thickness. Ophthalmology. 2010;117(11):2096-2103.

6. Chen S, Huang J, Wen D, Chen W, Huang D, Wang Q. Measurement of central corneal thickness by high-resolution Scheimpflug imaging, Fourier-domain optical coherence tomography and ultrasound pachymetry. Acta Ophthalmol. 2012;90(5):449-455.

7. Ishibazawa A, Igarashi S, Hanada $\mathrm{K}$, et al. Central corneal thickness measurements with Fourier-domain optical coherence tomography versus ultrasonic pachymetry and rotating Scheimpflug camera. Cornea. 2011;30(6):615-619.

8. Li H, Leung CK, Wong L, et al. Comparative study of central corneal thickness measurement with slit-lamp optical coherence tomography and Visante optical coherence tomography. Ophthalmology. 2008;115(5):796-801.

9. Amano S, Honda N, Amano Y, et al. Comparison of central corneal thickness measurements by rotating Scheimpflug camera, ultrasonic pachymetry, and scanning-slit corneal topography. Ophthalmology. 2006;113(6):937-941.

10. Huang J, Pesudovs K, Yu A, et al. A comprehensive comparison of central corneal thickness measurement. Optom Vis Sci. 2011;88(8):940-949. 
11. Kanellopoulos AJ, Asimellis G. In vivo three-dimensional epithelial imaging of corneal epithelium in normal eyes by anterior segment optical coherence tomography: a clinical reference study. Cornea. 2013;32(11):1493-1498.

12. Kanellopoulos AJ, Asimellis G. Correlation between central corneal thickness, anterior chamber depth, and corneal keratometry as measured by Oculyzer II and WaveLight OB820 in preoperative cataract surgery patients. J Refract Surg. 2012;28(12):895-900.

13. Kanellopoulos AJ, Asimellis G. Long term bladeless LASIK outcomes with the FS200 femtosecond and EX500 excimer laser workstation: the Refractive Suite. Clin Ophthalmol. 2013;7:261-269.

14. Rocha KM, Randleman JB, Stulting RD. Analysis of microkeratome thin flap architecture using Fourier-domain optical coherence tomography. J Refract Surg. 2011;27(10):759-763.

15. Yaylali V, Kaufman SC, Thompson HW. Corneal thickness measurements with the Orbscan topography system and ultrasound pachymetry. J Cataract Refract Surg. 1997;23(9):1345-1350.

16. Feng Y, Simpson TL. Comparison of human central cornea and limbus in vivo using optical coherence tomography. Optom Vis Sci. 2005; 82(5):416-419.

17. Sorbara L, Maram J, Fonn D, Woods C, Simpson T. Metrics of the normal cornea: anterior segment imaging with the Visante OCT. Clin Exp Optom. 2010;93(3):150-156.

18. Kiernan DF, Mieler WF, Hariprasad SM. Spectral-domain optical coherence tomography: a comparison of modern high-resolution retinal imaging systems. Am J Ophthalmol. 2010;149(1):18-31.

19. Grewal DS, Brar GS, Jain R, Grewal SP. Comparison of Scheimpflug imaging and spectral domain anterior segment optical coherence tomography for detection of narrow anterior chamber angles. Eye. 2011;25(5):603-611.

20. Vidal S, Viqueira V, Mas D, Domenech B. Repeatability and reproducibility of corneal thickness using SOCT Copernicus HR. Clin Exp Optom. 2013;96(3):278-285.

21. Francoz M, Karamoko I, Baudouin C, Labbé A. Ocular surface epithelial thickness evaluation with spectral-domain optical coherence tomography. Invest Ophthalmol Vis Sci. 2011;52(12):9116-9123.

22. Kanellopoulos AJ, Asimellis G. Introduction of quantitative and qualitative cornea optical coherence tomography findings induced by collagen cross-linking for keratoconus: a novel effect measurement benchmark. Clin Ophthalmol. 2013;7:329-335.

23. Shankar H, Taranath D, Santhirathelagan CT, Pesudovs K. Anterior segment biometry with the Pentacam: comprehensive assessment of repeatability of automated measurements. J Cataract Refract Surg. 2008;34(1):103-113.

24. Kanellopoulos AJ, Asimellis G. Comparison of Placido disc and Scheimpflug image-derived topography-guided excimer laser surface normalization combined with higher fluence CXL: the Athens Protocol, in progressive keratoconus. Clin Ophthalmol. 2013;7:1385-1396.
25. Kanellopoulos AJ, Asimellis G. Revisiting keratoconus diagnosis and progression classification based on evaluation of corneal asymmetry indices, derived from Scheimpflug imaging in keratoconic and suspect cases. Clin Ophthalmol. 2013;7:1539-1548.

26. Savini G, Carbonelli M, Barboni P, Hoffer KJ. Repeatability of automatic measurements performed by a dual Scheimpflug analyzer in unoperated and post-refractive surgery eyes. J Cataract Refract Surg. 2011;37(2):302-309.

27. Savini G, Carbonelli M, Sbreglia A, Barboni P, Deluigi G, Hoffer KJ. Comparison of anterior segment measurements by 3 Scheimpflug tomographers and 1 Placido corneal topographer. J Cataract Refract Surg. 2011;37(9):1679-1685.

28. Kanellopoulos AJ, Asimellis G. Three-dimensional LASIK flap thickness variability: topographic central, paracentral and peripheral assessment, in flaps created by a mechanical microkeratome (M2) and two different femtosecond lasers. Clin Ophthalmol. 2013;7:675-683.

29. Pavlin CJ, Harasiewicz K, Sherar MD, Foster FS. Clinical use of ultrasound biomicroscopy. Ophthalmology. 1991;98(3):287-295.

30. Avitabile T, Russo V, Ghirlanda R, Castiglione F, Marino A, Reibaldi A. Corneal oedemas: diagnosis and surgical planning with ultrasound biomicroscopy. Ophthalmologica. 1998;212 Suppl 1:13-16.

31. Avitabile T, Franco L, Ortisi E, et al. Keratoconus staging. A computerassisted ultrabiomicroscopic method compared with videokeratographic analysis. Cornea. 2004;23(7):655-660.

32. Rapuano CJ. Excimer laser phototherapeutic keratectomy in eyes with anterior corneal dystrophies: short-term clinical outcomes with and without an antihyperopia treatment and poor effectiveness of ultrasound biomicroscopic evaluation. Cornea. 2005;24(1):20-31.

33. Allemann N, Chamon W, Silverman RH, et al. High-frequency ultrasound quantitative analyses of corneal scarring following excimer laser keratectomy. Arch Ophthalmol. 1993;111(7):968-973.

34. Pavlin CJ, Foster FS. Ultrasound biomicroscopy. High-frequency ultrasound imaging of the eye at microscopic resolution. Radiol Clin North Am. 1998;36(6):1047-1058

35. Chawla B, Agarwal A, Kashyap S, Tandon R. Diagnosis and management of corneal keloid. Clin Experiment Ophthalmol. 2007;35(9): 855-857.

36. Reinstein DZ, Silverman RH, Coleman DJ. High-frequency ultrasound measurement of the thickness of the corneal epithelium. Refract Corneal Surg. 1993;9(5):385-387.

37. Germundsson J, Karanis G, Fagerholm P, Lagali NS. Age-related thinning of Bowman's layer in the human cornea in vivo. Invest Ophthalmol Vis Sci. 2013;54(9):6143-6149.

38. van den Berg TJ, van Rijn LJ, Michael R, et al. Straylight effects with aging and lens extraction. Am J Ophthalmol. 2007;144(3):358-336.
Clinical Ophthalmology

\section{Publish your work in this journal}

Clinical Ophthalmology is an international, peer-reviewed journal covering all subspecialties within ophthalmology. Key topics include: Optometry; Visual science; Pharmacology and drug therapy in eye diseases; Basic Sciences; Primary and Secondary eye care; Patient Safety and Quality of Care Improvements. This journal is indexed on Submit your manuscript here: http://www.dovepress.com/clinical-ophthalmology-journa

\section{Dovepress}

PubMed Central and CAS, and is the official journal of The Society of Clinical Ophthalmology (SCO). The manuscript management system is completely online and includes a very quick and fair peer-review system, which is all easy to use. Visit http://www.dovepress.com/ testimonials.php to read real quotes from published authors. 